August 2006

\title{
Insights from the 2006 Disease Management Colloquium
}

David B. Nash

Thomas Jefferson University

Robert A. Greene

Rochester Individual Practice Association, Inc.

Ronald R. Loeppke

CorSolutions

Nancy McCall

RTI International

Tracey Moorhead

Disease Management Association of America

Follow this and additional works at: https://jdc.jefferson.edu/healthpolicyfaculty

Part of the Health Services Research Commons

Let us know how access to this document benefits you

\section{Recommended Citation}

Nash, David B.; Greene, Robert A.; Loeppke, Ronald R.; McCall, Nancy; and Moorhead, Tracey, "Insights from the 2006 Disease Management Colloquium" (2006). College of Population Health Faculty Papers. Paper 31.

https://jdc.jefferson.edu/healthpolicyfaculty/31

This Article is brought to you for free and open access by the Jefferson Digital Commons. The Jefferson Digital Commons is a service of Thomas Jefferson University's Center for Teaching and Learning (CTL). The Commons is a showcase for Jefferson books and journals, peer-reviewed scholarly publications, unique historical collections from the University archives, and teaching tools. The Jefferson Digital Commons allows researchers and interested readers anywhere in the world to learn about and keep up to date with Jefferson scholarship. This article has been accepted for inclusion in College of Population Health Faculty Papers by an authorized administrator of the Jefferson Digital Commons. For more information, please contact: JeffersonDigitalCommons@jefferson.edu. 


\title{
Roundtable Discussion
}

\section{Insights from the 2006 Disease Management Colloquium}

\author{
Participants
}

\author{
David B. Nash, MD, MBA, Moderator \\ Dr. Raymond C. and Doris N. Grandon \\ Professor of Health Policy \\ Chairman, Department of Health Policy \\ Jefferson Medical College \\ Philadelphia, Pennsylvania
}

Robert A. Greene, MD

Associate Medical Director

Rochester Individual Practice Association, Inc.

Rochester, New York

Ronald R. Loeppke, MD, MPH

Chief Medical Officer

CorSolutions

Rosemont, IL

\author{
Nancy McCall, ScD \\ Chief Scientist \\ RTI International \\ Washington, DC \\ Tracey Moorhead \\ Executive Director \\ Disease Management Association of America \\ Washington, DC
}

This roundtable discussion emanates from the presentations given and issues raised at the 2006 Disease Management Colloquium, which was held May 10-12, 2006 in Philadelphia, Pennsylvania.

David Nash, MD, MBA: Our goal today is to provide an after-action report of the key themes and take-home messages from the Disease Management Colloquium to the readers of Disease Management.

Let's begin with Rob Greene. Rob, you were a presenter in the Pay-for-Performance and Other Incentives in Disease Management Programs track. Will you summarize the main messages from your presentation on the work of RIPA (Rochester Individual Practice Association) for us?

Robert A. Greene, MD: Sure. RIPA is a physician-led individual practice association with a pay-for-performance program. We tracked and reported on individual physician performance and we were involved with the Robert Wood Johnson Rewarding Results grant, so we used diabetes, coronary artery disease, and asthma as our chronic diseases.

There are two take-home lessons that we learned over these last few years that I will summarize for you. The first lesson is the importance of process in dealing with the physician. It took a great deal of very active, wellthought-out, relationship-centered work to get physician engagement. The second lesson is to give the physician specific action items.

In my presentation, I listed eight lessons for engaging physicians and making a successful program. For example, establishing goals and 
values, and treating physicians with respect. But what it comes down to is working with physicians through their anger and denial and issues with having grades. You have to respect that. We found that the physicians who made it through that process and moved on to acceptance actually were the ones who did better in our program. The key is using a relationship-centered process to help physicians get through their anger and denial and get to the point where they'll work with you.

We met with doctors from our family practice group and found that the ones who did well in this program indicated that they had taken the disease registries we provided and used the information. The doctors who didn't do well in the program were still angry; they hadn't worked through that. That's one lesson.

The second lesson is providing doctors with specific action items. We sent out patient-specific registries four times a year that gave doctors issues to work on.

A third lesson, which I touched on at the conference, was that the people who accepted the program also made system changes. Sometimes they were very minor, but they were low cost system changes. For example, the practice manager for one cardiology group took all the CAD (coronary artery disease) patients that we had sent them on CD, and used the information to make a chart extraction form. Their medical records people just went through those patients' charts and that group received a $4.0-$ a perfect score-in their first time out on the CAD measure.

So, there actually were three main points.

Dr. Nash: Follow-up question to you, Rob. What are the future plans for the pay-for-performance program at RIPA?

Dr. Greene: First, we would like to move to a Web-based system. We started out with many doctors not being Web enabled so we've had to work with a paper-based system.

Second, we want to connect our registries with disease management. I'd love to see the registries populated with predictive modeling numbers. We could identify the diabetics who are a five instead of a one in severity. Their physicians would have that information. We may pay those physicians whose patients have higher disease severity more for performance improvement.

Third, we're using a new analytic tool to find specific cost drivers and turning those into overuse quality measures. In diabetes care and asthma care, you're always trying to do morenot enough hemoglobin A1C's are done, not enough inhaled steroids. In some conditions, too much is done. For example, there's too much antibiotic use in treating sinusitis. When you can find a quality measure like that you can save costs and improve care right off the bat. Those are our future directions.

Dr. Nash: Great. Thank you, Rob. Now let's hear from Nancy McCall. Nancy, you were a key moderator at the meeting, and your track was concerned with the Medicare Health Support Program. Please share with us the principle messages you took away from the panel discussion and then we can talk about the future of Medicare health support. What did you hear from the field about how it's going?

Nancy McCall, ScD: I think our track was a little bit broader than Medicare Health Support. We started with the American College of Cardiology representative talking about Medicare Health Support, what their role has been to date, and their interest in being involved in the evaluation.

It was clear that they are interested in disease management and in helping to identify evidence-based metrics that can be used to monitor the quality of care provided to Medicare beneficiaries with congestive heart failure and diabetes. They believe that diabetes is clearly within their purview because they've found that there are very few diabetics who do not also have some sort of coronary artery disease.

They clearly think that the Medicare Health Support efforts will definitely benefit Medicare beneficiaries by focusing on managing hypertension and using appropriate medications. The same is true for diabetes, where the benefit will come from focusing on hemoglobin A1c management. They expect that the most important short-term outcomes will be to reduce emergency room visits and reduce hospitalizations by stabilizing people. 
The track also included Medicaid experience with disease management. This is where the audience became extremely engaged. There were presentations from Colorado, Rhode Island, and Florida, and people were really interested in the nuts and bolts of how to engage the Medicaid population because it is an extremely challenging population. A large portion of the attendees appeared to be from Medicaid programs. They wanted to hear from the different programs about such issues as creating culturally and linguistically appropriate material; not making any assumptions about the language skills of a Medicaid population; different mechanisms to reach out to the population, such as community workers as opposed to call centers; and which models might work better for different populations. There was a lot of interest in what's happening in the Medicaid programs.

Dr. Nash: Nancy, while you have the floor, would you speak a little bit about what you see as some of the challenges to the Medicare Health Support Program moving forward?

Dr. McCall: In my personal opinion, one of the issues is that this population is quite sick, and there will be a very high death rate in this population. The question becomes whether the Medicare Health Support Program is a viable business model. As the pilot goes forward, what will be the rules for increasing or refreshing the populations, or what will CMS (Centers for Medicare and Medicaid Services) do to allow additional beneficiaries to be added in? The programs have all "ramped up" and, as the population dies off, the question becomes how viable is that model.

Dr. Nash: Thank you, Nancy. That was great. Ron Loeppke, let's move on to you. You were a key participant in the Innovative Disease Management Products and Services track. Please summarize for us some of the take-home messages that you presented at the meeting.

Ronald R. Loeppke, MD, MPH: What I noticed, not only in the innovative track that I participated in but throughout other sessions that I was able to attend, is that a system transfor- mation is beginning to occur around the fundamental premise that it's more about population health management-improving the health of populations - as well as the quality of the care.

Those two fundamental pillars of prevention and evidence-based medicine quality improvement for those who already have a disease or condition seem to be the underlying initiative that's occurring-and occurring in several ways.

First, by aligning incentives among the key stakeholders, as we've already heard in some of the discussion about pay-for-performance for providers. Providers are one of the key stakeholders who are more actively engaged in quality improvement on the supply side. Second, on the demand side of health care, consumer or patient engagement and incentives can be much more aligned with the initiatives of the physicians. Trying to improve the quality of care for those who have chronic conditions, and trying to engage those who may not have a specific medical condition but who have definite high health risks and need to more actively participate in lowering those risks and improving their health.

Essentially, it's clearly emerging that good health is good business-and that good medicine is good business.

The value proposition that is beginning to emerge involves defining the business value of health. This goes beyond the traditional metrics of looking at the type of impact disease management initiatives have on reducing utilization or reducing medical and pharmacy costs. We need to look into what the employer community is asking for; how to help them get their arms around the health-related productivity losses they face due to absenteeism from work, as well as the impact of presenteeism, where workers are present but not as productive because their medical conditions are not well managed, or their health risks are out of control.

I think that broader value proposition of health and productivity types of metrics is an important one. One study we were able to talk about in my presentation showed that across the United States, on average, for every one dollar of direct medical/pharmacy costs em- 
ployers pay, they're paying approximately two-to-three dollars for health-related productivity losses due to absenteeism, presenteeism, and short- and long-term disability.

Dr. Nash: Ron, could you tell us what you feel are some of the most innovative disease management products or services coming down the pike?

Dr. Loeppke: I think what's interesting is the huge role that technology is continuing to play as more user-friendly solutions are coming into play for the consumer, as well as for the provider.

Some innovation is largely focused on datadriven solutions, allowing you to look at a lot of the different data components for a population, or even for an individual, and then be able to find a blueprint for action emerging from that analysis. The importance of innovation in the use of data and technology in that space, I think, continues to be demonstrated.

But just as important, though, is that integrated approaches now are becoming much more the norm. Instead of condition-specific disease management alone, there now is the ability to orchestrate evidence-based medicine approaches for individual conditions across a whole population-in terms of how to prevent those conditions from developing in the first place-and being able to touch the whole population with some health management types of initiatives.

Integration is also key with new innovation. I think the integration requires this technology and data management, and essentially distilling data into information. So, information is going to drive a lot of innovation.

Dr. Nash: Great. Thank you, Ron. Tracey Moorhead, you had the dubious distinction of trying to moderate all of the CEOs, and you did a great job. Will you tell us some of the main messages that you took away from the CEO panel at the end of the conference?

Tracey Moorhead: I would be glad to try, and inasmuch as anyone can moderate five CEO's I worked hard at it.

I asked the panelists to identify either a trend or a challenge for disease management that they see coming up in the future, and a couple of scenarios were presented. I thought that the panel was a great synopsis of all of the other excellent presentations that had occurred in the previous two and a half days.

Chris Selecky of Life Masters talked about the importance and the potential impact of the Medicare Health Support Program on disease management as a concept and as an industry. She talked about the potential negative impact on the industry if the pilot programs are not successful, but said that, in all likelihood, they would be successful and would show an improvement in the care of the beneficiaries who are participating.

She talked about the opportunity that these pilot programs, as opposed to demonstration projects, present to the industry and outlinedvery well, I thought-the work that the industry did to assist both Congress and CMS in developing them. She spoke briefly about the work that DMAA is doing to help CMS consider issues that need to be addressed as they develop Phase II of the Medicare Health Support Program, in which the existing pilots will be added to through a new round of contracting to provide similar services to additional Medicare beneficiaries.

Jim Pope from Healthways spoke very eloquently on the importance of establishing the proof of return on investment, or return of value, on disease management programs. He spoke generally about the efforts that have been under way for several years to ascertain the true impact of these programs on populations and the impact on the bottom line of the purchasers of these programs. He also spoke specifically about the DMAA's ongoing efforts to establish a methodology to measure the impact of disease management programs.

Dr. Fabius from I-trax spoke about the importance of implementing trusted physicians and the clinical setting in the workplace, and the integration of disease and care management programs directly in the workplace in the employer market. Knowing that this is a potential trend and a model for future care delivery, I thought his remarks were very intriguing-particularly his anecdote of the physician who simply couldn't walk down the hallway without being greeted and spoken to 
by employees in the company in which he was working, and the impact on health and productivity that the physical location of the clinician in the workplace can potentially have for those employers who choose to adopt this model.

I thought Dr. Bennett from Health Dialog really summed up quite a few of the presentations of the previous days by talking about the critical mass that he believes exists currently, pointing out that disease management has really proven itself as a clinical concept. There is a growing interest in disease management among large and mid-sized employers, health plans of all sizes, the federal government and state Medicaid programs, and now even internationally. There is interest in disease management programs, the implementation of programs, and the adoption of disease management. Having proven disease management as a concept really showcases and highlights the opportunities that exist to move forward.

Dr. Rizk from McKesson spoke about the impact of technology on disease management and the need for technological support services to assist in the provision of disease management applications.

I thought that the brief discussion we had regarding the definition of disease management that had been drafted by the DMAA and accepted widely over the last couple of years also was quite insightful. We highlighted some key phrases in the definition that addressed some of the issues that had been discussed over the previous couple of days, particularly the first part of the definition that notes that disease management supports the physician, emphasizes evidence-based practice guidelines and patient empowerment strategies, and evaluates outcomes.

I asked the panelists to comment on whether they found the definition to continue to be relevant to the disease management industry. There was an indication that, while the definition is still widely relevant, we may need to take a fresh look at it to make sure that we are supporting the physician with the proper integration of data-sharing systems, and integration of data into the physician's practice model. There also was a concern that perhaps we need to reinforce the population-based approach to disease management.
Finally, I think there was widespread agreement that the phrase itself, disease management, may need to be reconsidered both within the definition and as the name of the organization.

Dr. Nash: Great summary, Tracey. Thank you very much. Now, here is the final question for today. Will each of you share your perspective on the one-to-two main challenges for widespread adoption of disease management techniques in the future?

Tracey, may I start with you? I'm sure you think about this every day in your role as executive director of DMMA. What are the one or two main challenges that you see moving forward?

Ms. Moorhead: I see establishing a consensus methodology for evaluating the financial impact of disease management programs as one of the key challenges and, frankly, opportunities presented to the industry at this point.

We have outlined a process through which we will develop a methodology, inviting all stakeholders in the healthcare and disease management industry to participate with us, and we're very hopeful that we will be able to resolve this continuing conundrum.

The second most important challenge facing the industry is the relationship with physicians. We are working very hard to demonstrate the support and assistance that disease management programs certainly can provide to the physician-led healthcare team.

Dr. Nash: Great, Tracey. Thank you. Ron Loeppke-two major challenges to disease management moving forward?

Dr. Loeppke: I think that the issue of the metrics of looking at the impact of disease management continues to be a challenge. The sooner we can broaden the metrics to go beyond the traditional medical and pharmacy costs and utilization components and into broader health and productivity metrics, the better. This is an opportunity for the industry and one that's relevant for the employer community, who want to buy value from disease management initiatives. 
Once those metrics are broadened, I think that disease management is going to redefine itself. As was mentioned earlier by others, it will go beyond just managing the chronic conditions of a segment of the population-the $10 \%-15 \%$ of people-and more into working with $100 \%$ of the population, helping to identify and prevent those conditions and to get the business value for the health delivered.

The second challenge will center on the data and the actual technological limitations that are out there today for standardization and transfer of appropriate data for those measurements. It's going to require a whole new way to be able to get eligibility types of data "locked down" in order to look at the different return on investment metrics. Because of that, the industry has an opportunity to move into examining how the clinical transactions with both the physician and the patient or consumer can really be leveraged, rather than focusing on the financial transactions from such issues as benefit redesign or co-pay deductible distribution.

Dr. Nash: Thank you, Ron. And now to you, Nancy, for the wrap-up. What are two major challenges for disease management moving forward?

Dr. McCall: One challenge is how to engage consumers more actively at earlier stages of their diseases in order to prevent serious debilitating disease from occurring. There is much focus on how providers are doing with regard to making sure that their patients have certain metrics done, and guideline-concordant care, but I don't see a similar parallel effort to find ways of holding consumers equally accountable for their wellness. I think that how to get consumers motivated to do a better job at early intervention and preventing serious disease from developing is a challenge.

A second area has to do with the very chronically ill, like the older chronically ill who have many comorbid conditions. How do we measure health and improvement of health, and what realistic improvements should we be looking for in those people affected by 15 or more concurrent diseases? Figuring out what is an appropriate measure of overall improvement for very seriously ill people is a real challenge.

Dr. Nash: Outstanding. Well, in closing, let me thank Mary Ann Liebert for the support for this conference call. Thank you also to Nancy McCall, Robert Greene, Ron Loeppke, and Tracey Moorhead for joining us. I really appreciate you taking time from your busy schedules, and thanks again for your help during the Disease Management Colloquium. 